\title{
Molecular Analysis of Patient and Carrier Genes with Congenital Steroid 21-Hydroxylase Deficiency by Using Polymerase Chain Reaction and Single Strand Conformation Polymorphism
}

\author{
Toshihiro Tajima, ** Kenji Fujieda, ${ }^{\star}$ Kazuo Nakayama, * and Yoshiaki Fujii-Kuriyama * \\ *Department of Chemistry, Faculty of Science, Tohoku University, Aoba, Sendai, 980; and ${ }^{\ddagger}$ Department of Pediatrics, \\ School of Medicine, Hokkaido University, Sapporo 060, Japan
}

\begin{abstract}
Steroid 21-hydroxylase deficiency is a major cause of congenital adrenal hyperplasia and is caused by genetic impairment of this enzyme. Since $\sim \mathbf{8 0 \%}$ of cases are caused by point mutations of the CYP21B (CYP21A2) gene, whereas the remaining $20 \%$ are due to deletion of this gene, we used the polymerase chain reaction single strand conformation polymorphism technique for rapid and accurate diagnosis of this disease. Of 23 patients examined, 1 had a hemizygous CYP21B gene. 18 patient's genes localized their harmful mutations or deletion on both the alleles, while 4 of them found their causative mutations on one of the two alleles, and 1 failed to find any responsible mutation. All the mutations (four nucleotide substitutions) detected are also found in the CYP21A (CYP21A1) pseudogene. A mutation at the intron 2 site is most prevalent in both salt-wasting and simple virilizing forms of the disease, and accounts for $37 \%$ of the patient's genes $(17 / 46)$. Pedigree analysis of these mutations revealed that the mutations (at least four of them) occurred de novo at a considerable frequency on both the paternally and maternally inherited chromosomes. This result could explain occasional discordance of the diagnosis using HLA typing with the clinical symptoms. (J. Clin. Invest. 1993. 92:2182-2190.) Key words: congenital adrenal hyperplasia • 21-hydroxylase deficiency • polymerase chain reaction • single strand conformation polymorphism • de novo mutation
\end{abstract}

\section{Introduction}

Congenital adrenal hyperplasia $(\mathrm{CAH})^{1}$ is one of the most common forms of inborn metabolism error. Steroid 21-hydroxylase deficiency accounts for 90-95\% of CAH cases (1-3) and occurs at a frequency of $\sim 1$ in 15,000 births $(3,4)$. The symptoms of this disease are heterogeneous and are classified into three different clinical phenotypes: salt wasting (SW), simple virilizing (SV), and nonclassical (NC) forms. SW is the most

Address correspondence to Dr. Yoshiaki Fujii-Kuriyama, Department of Chemistry, Faculty of Science, Tohoku University, Aoba, Sendai, 980, Japan. 1993.

Received for publication 11 May 1992 and in revised form 7 June

1. Abbreviations used in this paper: $\mathrm{CAH}$, congental adrenal hyperplasia; NC, nonclassical; SSCP, single strand conformation polymorphism; SV, simple virilizing; SW, salt wasting.

J. Clin. Invest.

(c) The American Society for Clinical Investigation, Inc.

$0021-9738 / 93 / 11 / 2182 / 09 \$ 2.00$

Volume 92, November 1993, 2182-2190 severe form, in which cortisol and aldosterone synthesis is blocked, resulting in renal salt loss due to the lack of aldosterone and virilization due to accumulated adrenal androgen. SV, a less severe form, shows defective synthesis of only glucocorticoid with prominent features of virilization and sexual precocity $(5,6)$. NC is a milder form than the two others, but is extremely prevalent and characterized by the late onset of excessive androgen $(7,8)$. The clinical symptoms of this genetic disease may suggest different degrees of deficiency in steroidogenesis. Recent studies on the effects of various mutations in CYP21 activity and their distribution in the patient's genomes suggest that the three symptoms are somehow related to the degrees of the attenuated activities of mutated gene products $(9,10)$.

In the human genome, there are two genes, CYP21A (CYP21A1P) and CYP21B (CYP21A2), each of which is located adjacent to one of the two genes for the fourth component of the complement, $\mathrm{C} 4 \mathrm{~A}$ and $\mathrm{C4B}$, in the class III region of HLA complex. Of the two genes, CYP21B encodes an active enzyme, while CYP21A is a pseudogene with nine deleterious mutations (9-12).

DNA blot analysis using mutation-specific DNA probes or cloning and sequencing of the patient's genomic DNAs revealed that $15-20 \%$ of the cases result from deletion of the TaqI 3.7-kb band of the CYP21B gene, and the remaining $80-85 \%$ of the cases are caused by point mutations in the CYP21B genes (9-22). Interestingly, almost all the mutations identified so far in the patient's CYP21B genes are deleterious mutations found in the pseudogene (CYP21A gene). As suggested previously, these mutations are, most likely, products of gene conversion and/or homologous recombination events between the CYP2B and CYP21A genes, resulting in a high frequency of this genetic disease (13-16).

To further extend our study on the genetic deficiency of the CYP21 gene, we introduced the methods of PCR and single strand conformation polymorphism (SSCP) for accurate and rapid analysis of the patient's genomic DNAs (23-26). Here we report the usefulness of these methods for the diagnosis of genetic 21-hydroxylase deficiency and frequent generation of the defective CYP21B genes in the genetic transmission process revealed by family studies.

\section{Methods}

Patient. 23 steroid 21-hydroxylase deficiency patients were studied. Of 23 patients, we could analyze the parents of 18 . All the patients were diagnosed by elevated 17-hydroxyprogesterone and followed by the Department of Pediatrics of Hokkaido University, except for one (NC form), who was followed by Tenri Hospital (Tenri, Nara, Japan), and DNA of which was provided by Dr. Toshihiro Yakura (Tenri Hospital). We classified clinical symptoms of the patients into $\mathrm{SW}, \mathrm{SV}$, and $\mathrm{NC}$ forms according to the standard criteria (6). Informed consent was obtained from the families. 
DNA blot hybridization. Genomic DNA samples were prepared from blood leukocytes by a standard procedure (27). DNA was digested with the restriction endonuclease TaqI or Bgl II. The digests were subjected to $1.0 \%$ agarose gel electrophoresis and analyzed by the DNA blot analysis (28). The hybridization probe used was the 3.1-kb EcoRIBamHI genomic fragment, which was labeled with $\left[{ }^{32} \mathrm{P}\right]$ ATP by nick translation. Filters were hybridized and washed under conditions described previously (13). Then they were autoradiographed and hybridization signals were quantitated by densitometry using densitorol (DM-303; Advantec, Los Angeles, CA).

Nucleotide sequence analysis. The nucleotide sequence of the CYP21B gene from genomic DNA was determined directly with the PCR products by the chain termination method using appropriate sequencing primers. For the first PCR reaction followed by SSCP and direct sequencing analyses, the following primer pairs were used: A-B, C-D, and E-F ( Table II ). 30 cycles of PCR at $94^{\circ} \mathrm{C}$ for $60 \mathrm{~s}$ for denaturation, $58^{\circ} \mathrm{C}$ for $60 \mathrm{~s}$ for annealing, and $72^{\circ} \mathrm{C}$ for $120 \mathrm{~s}$ for polymerization were run. The PCR products were purified on a $1.0 \%$ agarose gel and were sequenced with Sequenase (United States Biochem. Corp., Cleveland, $\mathrm{OH}$ ) by the method of Owerbach et al. (19).

PCR-SSCP analysis. PCRs were performed with pairs of primers listed in Fig. 1 and Table II with $100 \mathrm{ng}$ of genomic DNA, $100 \mu \mathrm{M}$ each of dNTPs, $0.5 \mu \mathrm{M}$ of each pair of primers, $1.5 \mu \mathrm{M} \mathrm{MgCl}_{2}, 10 \mathrm{mM}$ Tris- $\mathrm{HCl}(\mathrm{pH} 8.3), 50 \mu \mathrm{M} \mathrm{KCl}, 0.25 \mathrm{U}$ of Taq polymerase, and $1 \mu \mathrm{l}$ of $\alpha-\left[{ }^{32} \mathrm{P}\right] \mathrm{dCTP}(3,000 \mathrm{Ci} / \mathrm{mmol}, 10 \mathrm{mCi} / \mathrm{ml})$ in a volume of $10 \mu \mathrm{l}(29-$ 31 ). For further analysis of the intron 2 mutation, the amplification using a primer pair of C-B was carried out for 30 cycles with each cycle of incubation consisting of $60 \mathrm{~s}$ at $94^{\circ} \mathrm{C}$ for denaturation, $60 \mathrm{~s}$ at $65^{\circ} \mathrm{C}$ for annealing, and then $90 \mathrm{~s}$ at $72^{\circ} \mathrm{C}$ for polymerization. For detailed analysis of the exon 4 mutation, each cycle of amplification consisted of incubation of $60 \mathrm{~s}$ at $94^{\circ} \mathrm{C}$ for denaturation, $60 \mathrm{~s}$ at $55^{\circ} \mathrm{C}$ for annealing, and $90 \mathrm{~s}$ at $72^{\circ} \mathrm{C}$ for polymerization using a primer pair of G-H. To further analyze two mutations in exon 8 , we first performed amplification with a primer pair of E-F ( 30 rounds of polymerization cycle consisting of $60 \mathrm{~s}$ at $94^{\circ} \mathrm{C}$ for denaturing, $60 \mathrm{~s}$ at $58^{\circ} \mathrm{C}$ for annealing, and $90 \mathrm{~s}$ at $72^{\circ} \mathrm{C}$ for extension) without labeling, and the amplified products were purified on $1.0 \%$ agarose gel. The purified fragments were reamplified using a primer pair of I-J (Table II) for detection of the nonsense mutation in exon 8. For detection of Arg to Trp mutation in exon 8 , the purified fragments were reamplified using a primer pair of K-L (Table 2). Reamplification reactions containing $\alpha-\left[{ }^{32} \mathrm{P}\right] \mathrm{dCTP}$ for labeling were subjected to 30 cycles of $60 \mathrm{~s}$ at $94^{\circ} \mathrm{C}$ for denaturation, $60 \mathrm{~s}$ at $60^{\circ} \mathrm{C}$ for annealing, and $90 \mathrm{~s}$ at $72^{\circ} \mathrm{C}$ for polymerization. The reaction mixture $(1 \mu \mathrm{l})$ was added to stop solution $(9 \mu \mathrm{l})$. Then, this solution $(2 \mu \mathrm{l})$ was heated in boiling water for $5 \mathrm{~min}$ for electrophoresis on $5 \%$ polyacrylamide-TBE ( $90 \mathrm{mM}$ Tris, $90 \mathrm{mM}$ Boric acid, and 2.5 mM EDTA) gels containing 5\% glycerol. The gel electrophoresis was performed at $30 \mathrm{~W}$ for $3 \mathrm{~h}$ at room temperature by cooling with fans for detection of the intron 2 mutation and two mutations in exon 8 . For analysis of the exon 4 mutation, the gel electrophoresis was run at $4^{\circ} \mathrm{C}$ for $6 \mathrm{~h}$. The gels were dried on Whatman paper (3MM) (Whatman International Ltd., Maido, England). Autoradiograph was performed for $72-96 \mathrm{~h}$ at $-30^{\circ} \mathrm{C}(30-33)$.

\section{Results}

Southern blot analysis of patient genomic DNA. We first investigated CYP21B genes of patients by DNA blot analysis. TaqI digestion of human genomic DNA generated two hybridizing fragments of 3.2 and $3.7 \mathrm{~kb}$ corresponding to the CYP21A pseudogene and CYP21 B gene, respectively, while Bgl II digestion generated $12-$ and $10-\mathrm{kb}$ bands from the CYP21A and CYP21B genes, respectively.

The results of the DNA blot analysis by restriction length polymorphism of TaqI and Bgl II are summarized in Table I (some of the analyses are shown in Figs. $5 A$ and $6 A$ ). Patient 22 genome lacked the 3.7-kb fragment, whereas in Bgl II digestion, the 10- and 12-kb bands were detected with the same intensity of hybridization signal (data not shown). These results indicate that gene conversion involving the TaqI sites occurred to the CYP21B gene of this patient. Patient 5 showed restriction patterns typical for heterozygous deletion of CYP21B as described previously $(15,34) ; 3.7-\mathrm{kb}$ TaqI and 12-kb Bgl II fragments were present with $\sim 50 \%$ reduction in the band intensity relative to $3.2-$ and $10-\mathrm{kb}$ fragments, respectively.

In our small group of patients the frequency of the gene deletion seems lower than the statistics reported previously. Generally speaking, the population of the deletion mutation in Japan seems to be lower than those reported in the United States $(10,15,18,19)$, as we also reported its lower incidence in another group of CYP21 deficiency $(9,13)$. A lower frequency of the gene deletion was also reported by Morel et al. (16).

Distribution of mutations. We next investigated the mutations in the patient's genes that gave a normal size TaqI or Bgl II fragment of the CYP21B gene and transmission in family pedigrees by PCR-SSCP and PCR direct sequencing according to Fig. 1. The entire sequences of the patient's genes were amplified by PCR and then subjected to both sequencing and SSCP analysis for confirmation of the mutations and for examination of the sensitivity of SSCP analysis. The results of all 23 patient's genes analyzed by direct sequencing in the present study were summarized in Table I.

Only four of the deleterious mutations that are present in the pseudogene (CYP21A) were found as responsible ones in

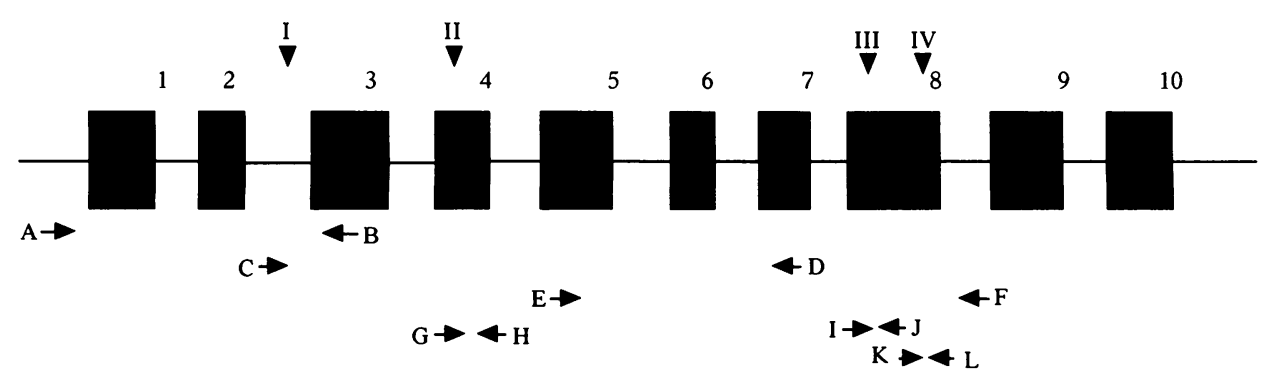

Figure 1. Human CYP21A2 gene structure and amplification strategy. The numbered boxes represent the exons. Oligonucleotide primers of A-L for PCR amplification are demonstrated by arrows. For PCR-direct sequencing the following primer pairs were used: A-B, C-D, and E-F. For PCR-SSCP analysis primer pairs of C-B, G-H, I-J, and $\mathrm{K}-\mathrm{L}$ were used. Strategy of PCR direct sequence and PCR-SSCP analysis is described in detail in Methods. Sequences of these primers are described in Table II. Arrowheads indicate four deleterious mutations that were detected by direct sequencing and PCR-SSCP in the present investigation. $(I)$ The intron 2 mutation that causes aberrant RNA splicing. (II) The substitution of Ile (codon 172) for Asn in exon 4. (III) The C to T transition in exon 8 results in the change Gln (codon 318) to the nonsense codon. (IV) The substitution of Arg (codon 356) for Trp. 
Table I. Molecular Defects of CYP21B Genes in the Patients

\begin{tabular}{|c|c|c|c|c|c|c|c|}
\hline \multirow[b]{2}{*}{ Patient } & \multirow[b]{2}{*}{ Disease type } & \multicolumn{2}{|c|}{ CYP21B gene } & \multicolumn{4}{|c|}{ Mutations } \\
\hline & & $\begin{array}{c}\text { TaqI } \\
(3.7 \mathrm{~kb})\end{array}$ & $\begin{array}{l}\text { BglII } \\
(12 \mathrm{~kb})\end{array}$ & Intron $2^{*}$ & $\begin{array}{l}\text { Exon } 4^{\ddagger} \\
\text { (Ile to Asn) }\end{array}$ & $\begin{array}{c}\text { Exon } 8^{8} \\
\text { (Gln to Non) }\end{array}$ & $\begin{array}{c}\text { Exon } 8^{\prime \prime} \\
\text { (Arg to Trp) }\end{array}$ \\
\hline 1 & SV & $+1+1$ & $+1+$ & +/-IIIII & $-1+^{n}$ & $-1-$ & $-1-$ \\
\hline 2 & SV & $+/+$ & $+/+$ & $-1-$ & $+1+$ & $-1-$ & $-1-$ \\
\hline 3 & SV & $++^{* *}$ & ++ & -- & ++ & -- & -- \\
\hline 4 & SV & $+/+$ & $+/+$ & $+/+$ & $-1-$ & $-1-$ & $-1-$ \\
\hline 5 & SV & $+/ 0^{\ddagger \ddagger}$ & $+/ 0$ & $+/ 0$ & -10 & -10 & $-/ 0$ \\
\hline 6 & SV & $+/+$ & $+1+$ & $+1-$ & $-1+$ & $-1-$ & $-1-$ \\
\hline 7 & SV & $+/+$ & $+/+$ & $-1+$ & $+1-$ & $-1-$ & $-1-$ \\
\hline 8 & SV & $+/+$ & $+/+$ & $+1-$ & $-1+$ & $-1-$ & $-1-$ \\
\hline 9 & SV & ++ & ++ & $+-* * *$ & -- & -- & -- \\
\hline 10 & SV & ++ & ++ & +- & -- & -- & -- \\
\hline 11 & SW & $+/+$ & $+/+$ & $+/+$ & $-1-$ & $-1-$ & $-1-$ \\
\hline 12 & SW & $+/+$ & $+/+$ & $-1-$ & $-1-$ & $+/+$ & $+1+$ \\
\hline 13 & SW & $+/+$ & $+/+$ & $-1-$ & $-1-$ & $+/+$ & $+1-$ \\
\hline 14 & SW & $+/+$ & $+/+$ & $-1-$ & $-1-$ & $+/+$ & $-1-$ \\
\hline 15 & SW & $+/+$ & $+/+$ & $-1-$ & $+1-$ & $-1+$ & $-1-$ \\
\hline 16 & SW & $+/+$ & $+/+$ & $-1-$ & $-1-$ & $-1-$ & $-1-$ \\
\hline 17 & SW & $+/+$ & $+1+$ & $+/+$ & $-1-$ & $-1-$ & $-1-$ \\
\hline 18 & SW & $+/+$ & $+1+$ & $+/+$ & $-1-$ & $-1-$ & $-1-$ \\
\hline 19 & SW & $+/+$ & $+/+$ & $+/+$ & $-1-$ & $-1-$ & $-1-$ \\
\hline 20 & SW & ++ & ++ & -- & -- & +- & -- \\
\hline 21 & SW & $+/+$ & $+/+$ & $-1-$ & $-1-$ & $+1-$ & $-1-$ \\
\hline 22 & SW & $-1-\$$ & $+/+$ & ND & ND & $-1-$ & $-1-$ \\
\hline 23 & NC & ++ & ++ & -- & ++ & -- & -- \\
\hline
\end{tabular}

* The change of $\mathrm{A}$ or $\mathrm{C}$ at the 655 th nucleotide to $\mathrm{G}$ causes aberrant RNA splicing. ${ }^{\ddagger} \mathrm{ATC}$ (codon 172), Ile is changed to AAC, Asn.

${ }^{8} \mathrm{Gln}$ (codon 318), CAG is changed to a nonsense codon, TAG. "Arg (codon 356), CTG is changed to Trp, TTG. ${ }^{\text {"***t\$5 }}$ CYP21B gene copy estimated on the basis of intensity of 3.7- and 3.2-kb TaqI, 12- and 10-kb BglII restriction fragments; ' $+/+$, family study was done; ** ++ , family study could not be done; $+/ 0$, a maternaly inherited chromosome is deleted; $-/-$, no band detected at $3.7 \mathrm{~kb}$ (TaqI digest). mutation present in paternal gene/mutation not present in maternal gene; $"-/+$, mutation not present in paternal gene/mutation present in maternal gene; ${ }^{* * *}+-$, mutation not localized in either paternal or maternal gene. Patients $1,6,7,8$, and 15 were diagnosed to be compound heterozygotes determined by the transmission of each mutation in pedigree analysis using PCR-SSCP analysis. ND, not done.

this group, and no other mutation was observed. Mutations of $\mathrm{C}$ or $\mathrm{A}$ to $\mathrm{G}$ in intron 2 were most frequently distributed both in SW and SV forms. Homozygotes of this mutation were found in the two types of patients (nos. $4,11,17,18$, and 19). In patient 5, who had one of the two alleles deleted, intron 2 mutation was detected. These results suggest that only the in vitro enzyme activity of the mutated gene products may not determine the clinical symptoms of this disease. As suggested previously $(9,10)$, however, the three other mutations are so distributed in the SW, SV, and NC forms that the degrees of the reduced enzyme activities in vitro of the mutated gene products are related to the severity of the clinical symptoms.

Exon 4 (Ile to Asn) mutations with a partial enzyme activity are all distributed in the SV and NC forms, except for patient 15 , in which exon 4 mutant is heterozygous with exon 8 nonsense mutant having no enzyme activity, while exon $8 \mathrm{mu}-$ tants (Gln to nonsense and Arg to Trp), neither of which has any enzyme activity, are distributed only in the SW form.

PCR-SSCP analysis of various mutations. PCR-SSCP is a rapid and sensitive method to analyze the sequence changes (29-32). PCR products were labeled by using ${ }^{32} \mathrm{P}$-labeled primers or deoxynucleotide. The labeled products were heat denatured and subjected to electrophoresis on nondenaturing polyacrylamide gel. Under these conditions the electrophoretic mobility of single-stranded DNA is affected by their nucleotide sequence and the temperature of electrophoresis (23-26).

PCR-SSCP analysis of the intron 2 mutation shows several bands of different mobilities, as shown in Fig. 2. Three bands were seen in patients $1,6,7$, and 8 , and seemed to indicate the heterozygosity, while patients $2,3,4$, and 5 had two bands, indicative of the homozygosity (23-26). Then, this portion of the CYP21B genes was subjected to direct sequencing to determine the nucleotide changes responsible for different mobilities of these bands. In patients 4 and 5 , only $G$ mutation was found, indicating either homozygosity (patient 4 ) or hemizygosity (patient 5 ) in this region, while patients $1,6,7$, and 8 were found to be heterozygous for the mutant $G$ and normal $A$. Furthermore, sequence analysis revealed that another nucleotide variation occurred in exon 3: Lys(AAG) to $\operatorname{Arg}(A G G)$ at codon 102. The substitution of Lys to Arg is known to be neutral for the enzyme activity $(19,22)$. Thus, the PCR-SSCP method proved to be useful for diagnosis of the intron 2 mutation. The remaining 15 patient's DNAs were also analyzed by PCR-SSCP with results shown in Table I.

For detection of the exon 4 mutation we used a primer pair of G-H in Table II and show the mobilities of single strand 


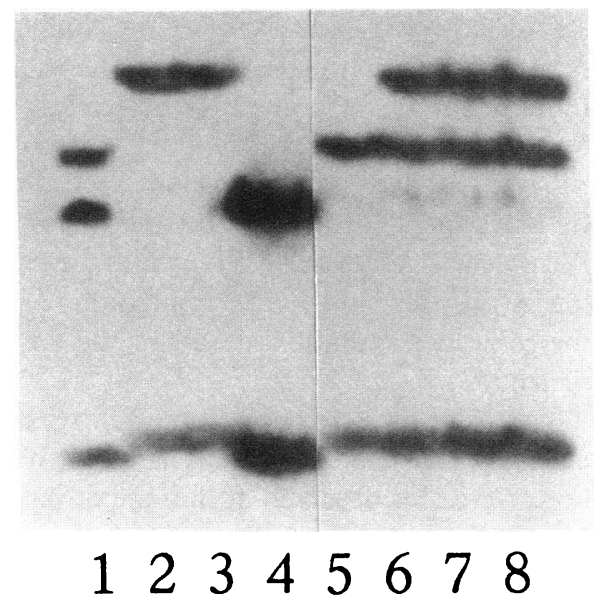

A
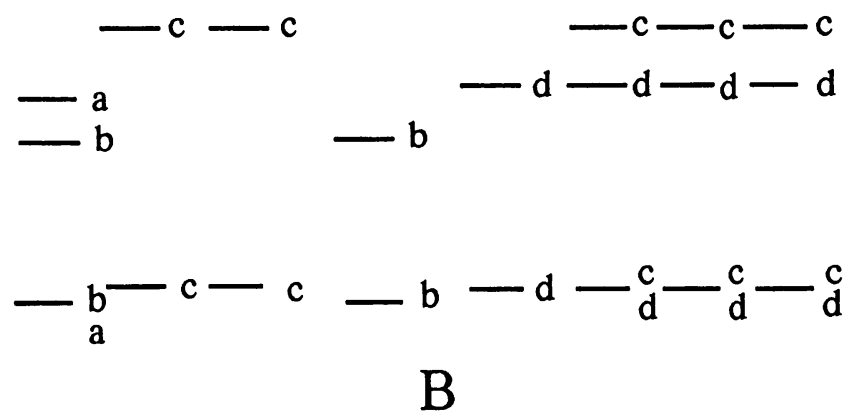

Figure 2. PCR-SSCP analysis of the intron 2 mutation. Genomic DNAs from 21-hydroxylase deficiency patients were subjected to PCR-SSCP analysis. Autoradiograph $(A)$ and the schematic representation of alleles $(B)$ are indicated. Lanes $1-9$ represent individuals in Table I. Four different migrating patterns result from the intron 2 mutation and neutral variation in exon 3: Lys or Arg at codon 102. These altered migrating bands were interpreted as follows. $(a)$ One allele that has A nucleotide at the intron 2 site and AGG at the codon 102 site; $(b)$ one allele that has $\mathrm{G}$ mutation at the intron site and AGG at codon 102; (c) one allele that has $A$ at the intron 2 site and AAG at the codon 102; $(d)$ one allele that has $\mathrm{G}$ mutation at the intron 2 site and AAG at the codon 102. The lower strands of $a$ and $b$ DNA showed the same mobility. The lower strands of $c$ and $d$ DNA showed the same mobility. Patient 4 was homozygous for intron 2 mutation, while patients $1,6,7$, and 8 were heterozygous, and patients 2 and 3 did not carry this mutation. Patients 5 and 6 had intron 2 mutation on a allele that is not deleted. These results of PCR-SSCP analysis were confirmed by direct sequence of the PCR-amplified fragments.

fragments in Fig. 3. The mobilities of bands of patients 2 and 3 can be distinguished from those of others. In every lane, the third band with an intermediate mobility was observed and appeared to be a different conformer of either the upper or lower strand that had the same sequence. The third band of the intermediate mobility from the DNA fragments was observed in all 23 patients analyzed. Different conformers of the same sequence with different mobilities have been reported to occur occasionally, probably depending on the nature of the sequence $(23-25,32)$.

Sequence analysis revealed a single nucleotide change in patients 2 and 3 at codon 172: ATC to AAC in exon 4. By
Table II. Sequences of Primers Used for PCR-SSCP Analysis

\begin{tabular}{clc}
\hline Primers & \multicolumn{1}{c}{ Sequence } & Position \\
\hline A & 5'-TCGGTGGGAGGGTACCTGAA-3' & $-122-103$ \\
B & 3'-AGGAACC血CTGATGAGGGACGA-5' & $722-700$ \\
C & 5'-AAGGTCAGGCCCTCAGCTGCCTTCA-3' & $606-630$ \\
D & 3'-GAGGACCTTCCCGTGCACGTGTA-5' & $1692-1688$ \\
E & 5'-AGAAGAGGGATCACATCGTGGAGAT-3' & $1364-1389$ \\
F & 3'-GAGGAAAAGACCGTCCTGCTGTT-5' & $2301-2278$ \\
G & 5'-GAGGAATTCTCTCTCCTCACTCAT-3' & $967-990$ \\
H & 3'-GAGGAAAAGACCGTCCTGCTGTT-5' & $1126-1104$ \\
I & 5'-TGGGCACCCTCACTCAGCTCTGA-3' & $1832-1854$ \\
J & 3'-TTCCTGGCACGTGCCGACGGGAA-5' & $2075-2051$ \\
K & 5'-AGGAGGAGCTAGACCACGAACTG-3' & $1995-2017$ \\
L & 3'-CGGGGTGGCGTGGTGTGCCGGGTCG-5' & $2153-2129$
\end{tabular}

Primers of A, B, C, and E are specific sequences for the CYP21B gene. Specific nucleotides for $B$ gene are showed by bold letters and are underlined. Primers B, D, F, H, I, J, and L are antisense strands. Primer pairs of A-B, C-D, and E-F are used for PCR-direct sequencing and SSCP. Primer pairs of C-B, G-H, I-J, and K-L are used for PCRSSCP analysis of I, II, III, and IV mutations in Fig. 1. Position indicates the nucleotide number as described previously (10). Strategy for PCR-SSCP analysis was described in detail in Methods.

PCR-SSCP analysis we could diagnose that patients 2 and 3 were homozygous for the exon 4 mutation, while patients 4,5 , and 9 did not carry this mutation.

Fig. 4 shows the results of PCR-SSCP analysis with the exon 8 region containing two mutations: CAG (codon 318 ) to TAG and CGG (codon 356) to TTG. To obtain a clear separation of electrophoretic bands, two sets of primers were used, respectively, for the two mutations. Taken together with the result of the direct sequencing, the PCR-SSCP analysis with the region containing codon 318 (Fig. $4 \mathrm{~A}$ ) shows that patients 11 and 16 are normal homozygotes in this region, while patients 12,13 , and 14 are mutant homozygotes and patient 15 is a heterozygote. The lower strands of these normal and mutant DNA fragments were not separated well in this and other attempts. Fig. 4 $B$ shows the results with the region containing codon 356 . Patients $11,14,15$, and 16 are normal homozygotes in this region, while patients 12 and 13 are a mutant homozygote and a heterozygote, respectively, in this region.

All these results clearly indicate that the PCR-SSCP provides a rapid and sensitive diagnosis for a single mutation in CYP21 deficiency genes.

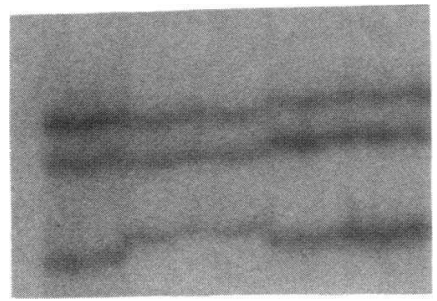

Figure 3. PCR-SSCP analysis of the exon 4 mutation. Patients 2 and 3 were homozygous for this mutation. Patients 9,4 , and 5 did not carry this mutation. Patient numbers are the same as described in Table I. In every lane, the third band with an intermediate mobility was observed and appeared to be a different conformer of either the upper or lower strand having the same sequence. 


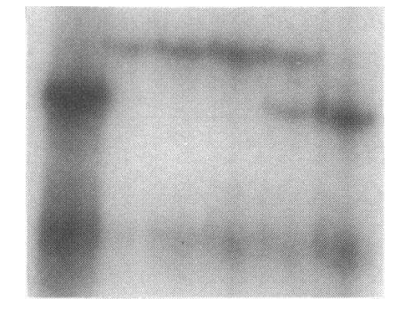

$12 \quad 13 \quad 14 \quad 151617$

A

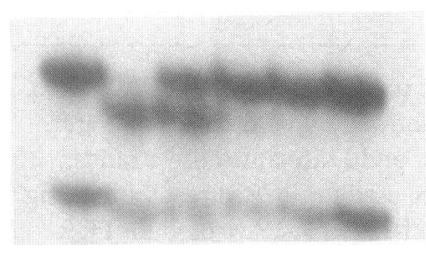

$\begin{array}{llllll}12 & 13 & 14 & 15 & 16 & 17\end{array}$

B
Figure 4. PCR-SSCP analysis of two mutations in exon 8. (A) PCR-SSCP analysis of the nonsense mutation. Patients 12,13 , and 14 were homozygous for this mutation. Patients 16 was heterozygous for this mutation. Patients 11 and 16 did not carry this mutation. (B) PCR-SSCP analysis of the missense mutation (Arg to Trp) in exon 8. Patient 12 was homozygous for this mutation. Patient 13 was heterozygous for this mutation. Patients 11,

Pedigree analysis of mutations. To understand the high frequency of incidence of genetic CYP21 deficiency, we investigated genetic transmission of these mutations by pedigree analysis. Table III summarizes the results of the intron 2 mutation. Surprisingly, de novo mutation of $A$ or $C$ to $G$ was found to occur at a considerable frequency ( 2 in 10 examined cases) in the genetic transmission process. Representative analysis of patient 19's family is demonstrated in Fig. 5. In DNA blot analysis shown in Fig. $5 A$, the intensity of the 3.7-kb TaqI and 10-kb Bgl II bands demonstrated no gross alternation or deletion in either of the two CYP21B genes in the patient genome as well as those of the parents (densitometric analysis showed that the ratios in the band intensity of 3.7 and $3.2 \mathrm{~kb}$ are 1.0:1.0, 1.0:1.3, and 1.0:1.3 for I-1, I-2, and II-1, respectively, and that those of 10 and $12 \mathrm{~kb}$ are $1: 1$ for all the family members). The entire sequence of the CYP21B gene of the patient was then amplified by a series of the primer pairs as described in Methods and subjected to the direct sequencing and SSCP analysis. The region containing the responsible mutation was amplified by a primer pair of C-B. To amplify equally the sequences of the two alleles of the CYP21b gene by the C-B primer, the sequences of parental as well as patient's genes containing the $C$ and $B$ primer sites were first amplified by primer pairs, $A-B$ and C-D, respectively, and confirmed by the direct sequencing. Since two mutation sites (intron 2 and codon 102) are included in this region, as described in Fig. 2, electrophoretic patterns of SSCP appear to be a little complex ( $\mathrm{I}-1$ is a homozygote with $A$ at intron 2 [655] and $G$ at codon $102, I-2$ is a heterozygote with $G$ and $A$ at intron 2 and $G$ and $A$ at codon 102 , respectively, and II-1 is a homozygote with $\mathrm{G}$ at intron 2 and $G$ at codon 102) as seen in Fig. 5 B. The maternal genotype shows heterozygosity for the intron $2 \operatorname{site}(A$ and $G$ ), while the paternal is a normal homozygote for the site of the intron 2 mutation, suggesting that the mutation occurred de novo on the paternally transmitted chromosome. The direct sequencing

analysis (Fig. $5 \mathrm{C}$ ) of the concerned region confirmed the above suggestion. The HLA typing and DNA fingerprinting using the minisatellite myoglobin 33-repeated probe (35) (data not shown) also corroborated the family relations. The same analyses were carried out with patient 7 . The intron 2 mutation, G, was generated de novo on the maternally inherited CYP21B gene (Tables I and III), while the paternally inherited gene carried the exon 4, T to A mutation (36). The compound heterozygous mutations result in the SV type of CYP21B deficiency.

Pedigree analysis of the nonsense mutation in exon 8 was also performed and the results are summarized in Table III. De novo mutations were also observed at this site of patients 12 and 14. Representative analyses of patient 12's family are demonstrated in Fig. 6. The maternal genotype shows heterozygosity in this region, while the paternal is a normal homozygote at the exon 8 site. DNA blot analysis of the genomic DNA using TaqI and BglII enzymes showed no deletion of the two allelic CYP21B genes in the patient and the parental genomes as shown in Fig. $6 \mathrm{~A}$. The sequence identity used for $\mathrm{I}$ and $\mathrm{J}$ primers in the patient and parental genes was also confirmed by the direct sequencing. These results strongly suggested that the mutant homozygosity at the exon 8 mutation site of the patient was not due to unilateral amplification of one of the two allelic CYP21B genes, but to the de novo mutation C to $T$ on the paternally transmitted chromosome. The HLA typing

Table III. Pedigree Analysis of Intron 2 and Exon 8 Nonsense Mutation

\begin{tabular}{|c|c|c|c|c|c|c|}
\hline \multirow[b]{2}{*}{ Mutation } & \multicolumn{2}{|c|}{ Patient } & \multicolumn{2}{|c|}{ Father } & \multicolumn{2}{|c|}{ Mother } \\
\hline & $\begin{array}{l}\text { CYP21B } \\
\text { gene }\end{array}$ & Mutation & $\begin{array}{l}\text { CYP21B } \\
\text { gene }\end{array}$ & Mutation & $\begin{array}{c}\text { CYP21B } \\
\text { gene }\end{array}$ & Mutation \\
\hline \multicolumn{7}{|l|}{ Intron 2} \\
\hline 1 & $+/+$ & $+1-$ & ++ & +- & ++ & -- \\
\hline 4 & $+/+$ & $+/+$ & ++ & +- & ++ & +- \\
\hline 5 & $+/ 0$ & $+/ 0$ & ++ & +- & +0 & -0 \\
\hline 6 & $+/+$ & $-1+$ & ++ & -- & ++ & +- \\
\hline $7^{*}$ & $+/+$ & $-1+$ & ++ & -- & ++ & -- \\
\hline 8 & $+/+$ & $+1-$ & ++ & +- & ++ & -- \\
\hline 11 & $+/+$ & $+/+$ & ++ & +- & ++ & +- \\
\hline 17 & $+/+$ & $+/+$ & ++ & +- & ++ & +- \\
\hline 18 & $+/+$ & $+/+$ & ++ & +- & ++ & +- \\
\hline $19^{*}$ & $+/+$ & $+/+$ & ++ & -- & ++ & +- \\
\hline \multicolumn{7}{|l|}{ Exon 8} \\
\hline $12^{*}$ & $+/ t$ & $+1+$ & ++ & -- & ++ & +- \\
\hline 13 & $+/+$ & $+/+$ & ++ & +- & ++ & +- \\
\hline $14^{*}$ & $+/+$ & $+/+$ & ++ & +- & ++ & -- \\
\hline 15 & $+/+$ & $+1-$ & ++ & +- & ++ & -- \\
\hline 21 & $+/+$ & $+1-$ & ++ & +- & ++ & -- \\
\hline
\end{tabular}

Numbers of patients correspond to those in Table I. CYP21B gene copy estimated on the basis of intensity of 3.7- and 3.2-kb TaqI, 10and 12-kb BglII restriction fragments. $+/+$, inherited chromosome is determined by a family study; $+/ 0$, a maternaly inherited chromosome is deleted; $+/-$, mutation present in paternal gene/no mutation in maternal gene; $-/+$, no mutation in paternal gene/mutation present in maternal gene;,,+++--- , family study was not done. ${ }^{*} \mathrm{De}$ novo mutation in the paternally or maternally transmitted chromosome. 


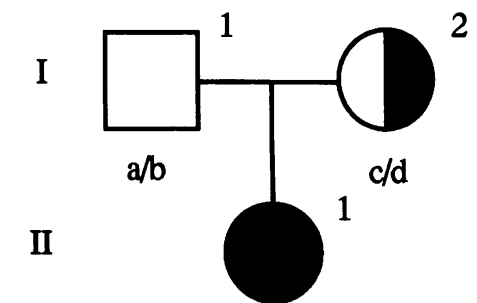

$\mathrm{b} / \mathrm{c}$

\section{a: $\mathrm{A} 2 \quad \mathrm{~B} 44 \quad \mathrm{BL} \quad \mathrm{C} 4 \mathrm{~A} 3 \quad \mathrm{C} 4 \mathrm{~B} 1$ \\ b: A31 Bw61 Cw3 C4A3 C4BQ \\ c: A24 B7 $\quad$ Cw7 C4A3 C4B5 \\ d: A3 Bw52 Cw1 C4A3 C4BQ0}

Taq I

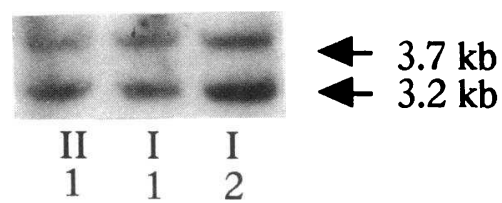

Bgl II

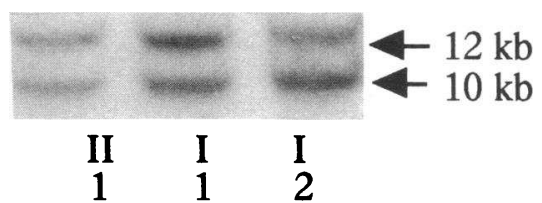

$\mathbf{A}$

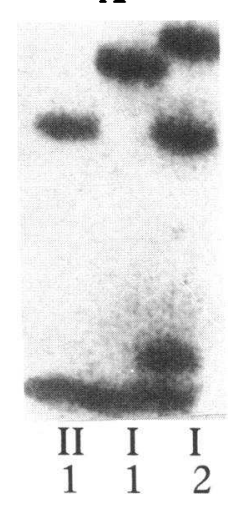

B

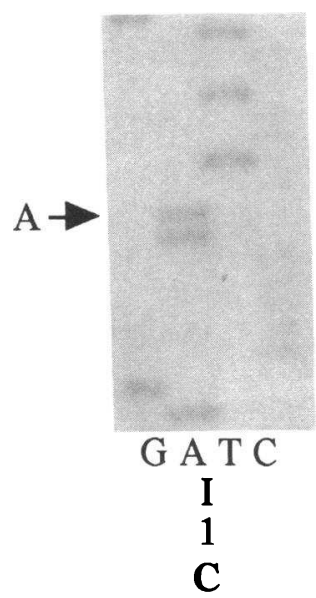

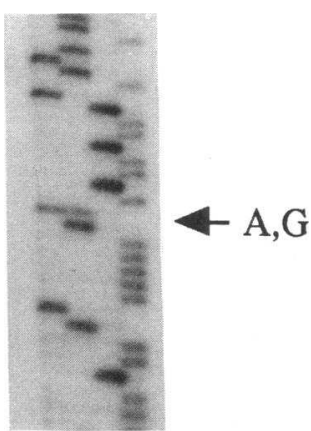

G A T C I II

and DNA fingerprinting using a minisatellite myoglobin 33repeated probe (35) (data not shown) confirmed the family relation of the subjects examined. De novo mutation during the hereditary process was not only found at the two mutation sites, as described, but also at the exon 4 site (Ile to Asn) (data not shown).

\section{Discussion}

Of the high incidence of congenital steroid 21-hydroxylase deficiency, about $\leq 20 \%$ is accounted for by the deletion of the

Figure 5. Transmission of the intron 2 mutation in patient 19 family. $(A)$ DNA blot analysis of genomic DNAs. TaqI-digested DNA: lane $I-1$, patient DNA; lane $I I-1$, father DNA; lane I-2, mother DNA. Bgl IIdigested DNA: lane $I-1$, patient DNA; lane II-1, father DNA; lane I-2, mother DNA. ( $B$ ) PCR-SSCP analysis. PCR-SSCP screening demonstrated that patient II-1 was homozygous for this mutation. In this family, the mother of I-2 showed a $b$ and $c$ pattern in Fig. 2, therefore, she was diagnosed heterozygous for this mutation. However, the father of I-1 showed an $a$ pattern in Fig. 2, so he did not carry this mutation. Patient II-1 was homozygous for this mutation. Square, male; circles, females; filled symbol, patient; halffilled symbol, carrier. $(C)$ Nucleotide sequence of a portion of intron 2 from family members. Arrows point to the $A$ to $G$ transition at the intron 2 site. II-1 is homozygous for this mutation. In the I-2 sequence ladder, the normal $A$ and mutant $G$ nucleotide are present. I-1 shows the normal A nucleotide. responsible gene and the remaining portion is considered to be caused by point mutations. Although there is controversy about the frequency of gene deletion, the group of the patients examined here has a lower frequency of the gene deletion, with only one case of heterozygous deletion of the CYP21B gene locus examined by the DNA blot analysis. Our previous report on another group of patients in Japan also showed a lower frequency of the gene deletion $(9,13)$. These results suggest that the frequency of the gene deletion in the CYP21 deficiency in Japan is lower than those reported in the United States (10, $15,18,19)$, although a lower frequency of the deletion was also 


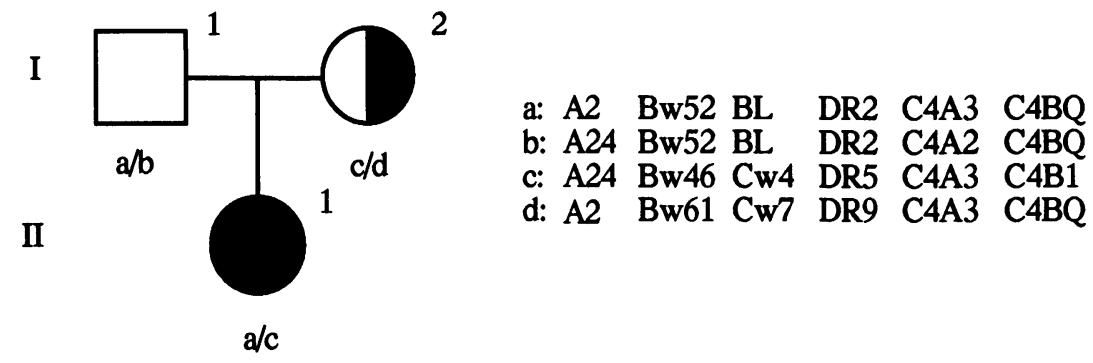

Taq I

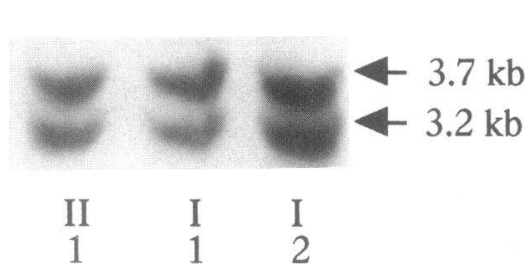

A

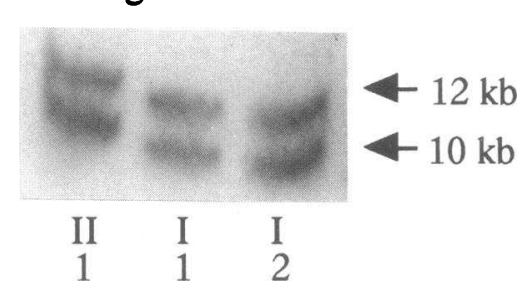

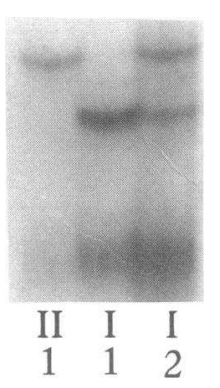

B
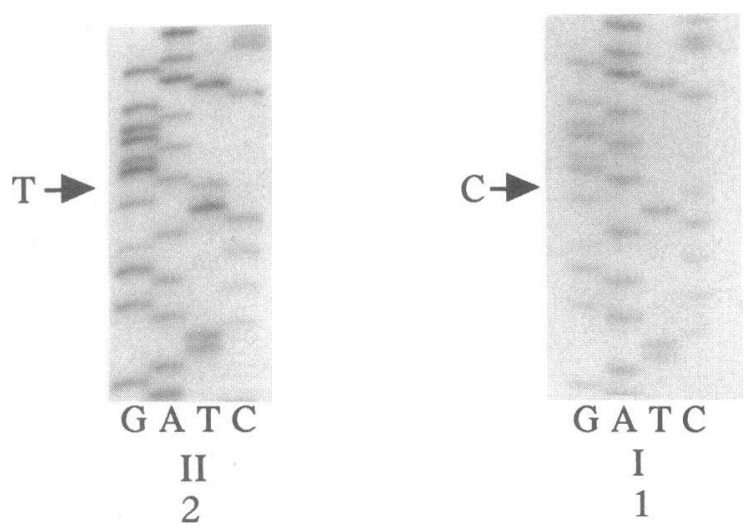

C

reported by Morel et al. (16) in United States. Therefore, for the accurate and rapid diagnosis of this genetic disease, it is necessary to develop a simple, sensitive, and accurate method to detect point mutations in the patient's genes. When it is taken into consideration that almost all the responsible mutations identified so far in the patient's genes are considered to be brought in from the pseudogene by gene conversion or homologous recombination events, the PCR-SSCP method may be suitable for this purpose since it uses a limited number of primer pairs to amplify the entire sequence of the CYP21B gene as efficiently as possible by discriminating against the CYP21A pseudogene. The combinations of primer pairs described in Methods do not amplify the sequences of the pseudogene under those conditions.
Figure 6. Transmission of the nonsense mutation of exon 8 in patient 12 family. ( $A$ ) DNA blot analysis of genomic DNAs. TaqI-digested DNA: lane $I-1$, patient DNA: lane II-1, father DNA; lane I-2, mother DNA. BglII-digested DNA: lane $I-1$, patient DNA; lane $I I-1$, father DNA; lane I-2, mother DNA. BglIIdigested DNA: lane $I-1$, patient DNA; lane $I I-1$, father DNA; lane I-2, mother DNA. (B) PCR-SSCP screening. Patient II-1 was homozygous for this mutation. In this family II-2 was heterozygous, whereas I-1 did not carry this mutation. $(C)$ Nucleotide sequence of a portion of exon 8 from family members. Arrows point to the $\mathrm{C}$ to $\mathrm{T}$ transition site at the first nucleotide of codon 318. II-1 is homozygous for this mutation. In the I-2 sequence ladder, the normal $\mathrm{C}$ and mutant $\mathrm{T}$ are at this position. In the I-1, only normal $\mathrm{C}$ nucleotide is present.
The PCR products along the entire sequences of the 23 patient's CYP21B genes were subjected to SSCP analysis or to direct sequencing. As summarized in Table I, 19 of 23 patients localized their responsible mutations or deletions on their two alleles, whereas four of them (patients 9, 10, 20, and 21) missed one responsible mutation, and none of the mutations was localized in patient 16 . Since the primers used for PCR were synthesized for specific amplification of the CYP21B structural gene including introns, the missing responsible mutations could be found in the $5^{\prime}$ upstream or $3^{\prime}$ downstream flanking regulatory region of this gene.

The intron 2 mutation causes aberrant splicing in the maturation process of $\mathrm{mRNA}$ and is by far the most prevalent of all mutations identified $(9,10,18,19)$. In one patient (no. 5) of 
the SV form, one allele was deleted, while the other allele had the intron 2 mutation. If the enzyme activity of the mutant genes estimated by the transfection experiments (9) was a sole determinant of the clinical symptoms of the CYP21 deficiency, the results of molecular analysis would suggest that these patients showed the SW form. Considering this result and that homozygotes for this mutation were found in both the SW and SV form, it should be noted that some factor other than the enzyme activity estimated in vitro may also work as a determinant of the clinical symptom. In other cases, however, three other mutations are so distributed in the classified forms of the patients that reduced levels of the enzyme activity of the mutated gene products are related to severity of the clinical symptoms as described previously (9). In other words, the enzyme activity of the mutated gene products is mainly involved in determination of the clinical symptoms $(9,10)$. Therefore, identification of mutations may lead to prediction of the classified form of the clinical symptoms in the prenatal diagnosis as suggested. As shown in Figs. 2-6, SSCP profiles are sensitive enough to detect a single mutation in the sequence up to $\sim 500$ bp. This method is simple and rapid, and is very useful for systematic screening of point mutations with a limited number of primer pairs, because almost all the mutations identified so far in the patient's genes correspond to one of the eight point mutations and 8-bp deletion in the pseudogene.

Pedigree analysis of these mutations revealed that de novo or sporadic mutations for all the three sites (the intron 2, exon 4 , and exon $8 \mathrm{Gln}$ to nonsense) occur at a considerable frequency, although the number of the examined cases is very limited. In three of the four cases reported, the de novo mutations of the patients occurred at the same sites of the allelic gene as that of the carrier parent, while the remaining one was generated at a different site. Although it remains to be studied whether de novo mutations are likely to occur at the same site of the allelic gene, it is interesting to note that homozygous mutations were observed in the patient's genomes at higher frequency than that calculated from random combinations of the frequency of those mutations $(9,10,18,19)$. These de novo mutations appear to occur on both the maternally and paternally inherited chromosomes. Because they are all found in the pseudogene, these mutations are considered to be products of the gene conversion events but not to be bona fide point mutations, and explain at least in part the reason for high incidence of the genetic 21-hydroxylase deficiency. It remains to be studied what molecular mechanism frequently causes the gene conversion in this region or whether there is any specific sequence to facilitate the gene conversion event.

Close genetic linkage of the 21-hydroxylase deficiency of HLA complex has been known and HLA typing is now conventionally used for the prenatal diagnosis $(5,6,34,37)$. It has been reported, however, that marked discordance between clinical features and diagnoses predicted from HLA typing was found in some families that have affected and unaffected siblings with the identical HLA haplotypes $(38,39)$. Most of such cases could be explained by de novo mutations due to gene conversion mechanism $(10,38)$. Indeed, this is found to be the cases with patient 8 's family, which has affected and unaffected siblings with identical HLA types (36).

In general, while it has been revealed that $\sim 90 \%$ of the patient's genes with the genetic 21-hydroxylase deficiency can be explained by either the causative point mutations from the pseudogene or deletion mutations, no mutation responsible for the remaining $10 \%$ of the patient's genes has yet been identified. Recently, some mutations that were not present in the pseudogene were identified $(40,41)$. It is possible that the remaining $10 \%$ of patient's genes have new mutations that do not exist in the pseudogene. To establish as perfect diagnosis by PCR-SSCP as possible, it is essential to identify the missing causative mutations for the remaining patient's genes.

\section{Acknowledgment}

We thank Drs. R. Kominami (Niigata University Medical School, Niigata) and Y. Nakamura (Cancer Institute, Tokyo) for their valuable advice in DNA fingerprinting and providing DNA probes. Our sincere thanks are also due to Dr. K. Hayashi (National Cancer Center Research Institute, Tokyo) for his advice in PCR-SSCP.

This work was supported in part by a Grant-in-Aid for Scientific Research from the Ministry of Education, Science and Culture of Japan.

\section{References}

1. White, P. C., M. I. New, and B. Dupont. 1987. Congenital adrenal hyperplasia. N. Engl. J. Med. 316:1519-1524 and 1580-1586.

2. New, M. I., P. C. White, S. Pang, B. Dupont, and P. W. Speiser. 1989. The adrenal hyperplasia. In The Metabolic Basis of Inherited Disease, 6th ed. C. R. Scriver, A. Beaudet, S. Sly, and D. Valle, editors. McGraw-Hill Inc., New York. 1881-1917.

3. White, P. C., C. Crawford, and M. I. New. 1989. Steroid 21-hydroxylase deficiency. Curr. Opin. Pediatr. 1:436-440.

4. Pang, S., M. A. Wallace, L. Hofman, H. C. Thuline, C. Dorche, I. C. T. Lyon, R. H. Dobbind, S. Kling, K. Fujieda, and S. Suwa. 1988. Worldwide experience in newborn screening for classical congenital adrenal hyperplasia due to 21-hydroxylase deficiency. Pediatrics. 81:866-874.

5. Miller, W. L., and Y. Morel. 1989. The molecular genetics of 21-hydroxylase deficiency. Annu. Rev. Genet. 23:371-393.

6. Miller, W. L., and L. S. Levine. 1987. Molecular and clinical advances in congenital adrenal hyperplasia. J. Pediatr. 111:1-17.

7. Speiser, P. W., M. I. New, and P. C. White. 1988. Molecular genetic analysis of nonclassical steroid 21-hydroxylase deficiency associated with HLA-B14, DR1. N. Engl. J. Med. 319:19-23.

8. Speiser, P. W., B. Dupont, B. Rubinstein, A. Piazza, A. Kastelan, and M. I. New. 1985. High frequency of nonclassical 21-hydroxylase deficiency. Am. J. Hum. Genet. 37:650-667.

9. Higashi, Y., T. Hiromasa, A. Tanae, T. Miki, J. Nakura, T. Kondo, T. Ohura, E. Ogawa, K. Nakayama, and Y. Fujii-Kuriyama. 1990. Effects of individual mutations in the P-450 (C21) pseudogene the P-450 (C21) activity and their distribution in the patient genomes of congenital steroid 21-hydroxylase defciency. J. Biochem. (Tokyo). 109:638-644.

10. Speiser, P. W., B. Dupont, D. Zhu, J. Serrat, M. Buegeleisen, M. T. Tusie-Luna, M. Leser, M. I. New, and P. C. White. 1992. Disease expression and molecular genotype in congenital adrenal hyperplasia due to 21 -hydroxylase deficiency. J. Clin. Invest. 90:584-595.

11. Higashi, Y., H. Yoshioka, M. Yamane, O. Gotoh, and Y. Fjii-Kuriyama. 1986. Complete nucleotide sequence of two steroid 21-hydroxylase genes tandemly arranged in human chromosome: a pseudogene and a genuine gene. Proc. Acad. Natl. Sci. USA. 83:2841-2845.

12. White, P. C., D. Grossberger, B. J. Onufer, D. D. Chapline, M. I. New, B. Dupont, and J. L. Strominger. 1985. Two genes encoding steroid 21-hydroxylase are located near the genes encoding the fourth component of complement in man. Proc. Natl. Acad. Sci. USA. 82:1089-1093.

13. Higashi, Y., A. Tanae, H. Inoue, and Y. Fujii-Kuriyama. 1988. Evidence for frequent gene conversions in the steroid 21-hydroxylase $(\mathrm{P}-450 \mathrm{C} 21)$ gene: implications for steroid 21-hydroxylase deficiency. Am. J. Hum. Genet. 42:1725.

14. Harada, F., A. Kimura, T. Iwanaga, K. Shinozawa, J. Yata, and T. Sasazuki. 1987. Gene conversion-like events cause steroid 21-hydroxylase deficiency in congenital adrenal hyperplasia. Proc. Natl. Acad. Sci. USA. 85:8091-8094.

15. White, P. C., A. Vitek, B. Dupont, and M. I. New. 1988. Characterization of frequent deletions causing steroid 21-hydroxylase deficiency. Proc. Natl. Acad. Sci. USA. 85:4436-4440.

16. Morel, Y., J. Andre, B. Uring-Lambert, G. Hauptman, H. Geutel, M. Tosi, M. G. Forest, M. David, J. Bertrand, and W. L. Miller. 1989. Rearrangements and point mutations of $\mathrm{P} 450 \mathrm{C} 21$ genes are distinguished by five restriction endonuclease haplotypes identified by a new probing strategy in 57 families with congenital hyperplasia. J. Clin. Invest. 83:527-536. 
17. Sinnott, P., S. Collier, C. Costigen, P. A. Dyer, R. Harris, and T. Strachan. 1990. Genesis by meiotic unequal crossover of a de novo deletion that contributes to steroid 21-hydroxylase deficiency. Proc. Natl. Acad. Sci. USA. 87:2107-2111.

18. Mornet, E., P. Crete, F. Kuttenn, M. C. Raux-Demay, J. Boue, P. C. White, and A. Boue. 1991. Distribution of deletions and seven point mutations on CYP21B genes in three clinical forms of steroid 21-hydroxylase deficiency. Am. J. Hum. Genet. 48:79-88.

19. Owerbach, D., Y. M. Crawford, and M. B. Draznin. 1990. Direct analysis of CYP21B genes in 21-hydroxylase deficiency using polymerase chain reaction amplification. Mol. Endocrinol. 4:125-131.

20. Chiou, S. H., M. C. Hu, and B. Chung. 1990. A missense mutation at Ile 172-Asn or Arg 356-Trp causes steroid 21-hydroxylase deficiency. J. Biol. Chem. 265:3549-3552.

21. Amor, M., K. L. Parker, H. Globerman, M. I. New, and P. C. White. 1988. Mutation in the CYP21B gene (Ile-Asn) causes steroid 21-hydroxylase deficiency. Proc. Natl. Acad. Sci. USA. 84:1600-1604.

22. Higashi, Y., A. Tanae, H. Inoue, T. Hiromasa, and Y. Fujii-Kuriyama. 1988. Aberrant splicing and missense mutations cause steroid 21-hydroxylase [P450(C21)] deficiency in humans. Proc. Natl. Acad. Sci. USA. 85:7486-7490.

23. Orita, M., Y. Suzuki, T. Sekiya, and K. Hayashi. 1989. A rapid and sensitive detection of point mutations and genetic polymorphisms using polymerase chain reaction. Genomics. 5:874-879.

24. Murakami, Y., M. Katahira, R. Makino, K. Hayashi, H. Hirohashi, and T. Sekiya. 1991. Inactivation of the retinoblastoma gene in a human lung carcinoma cell line detected by single strand conformation polymorphism analysis of the polymerase chain reaction product conformation polymorphisms. Proc. Natl. Acad. Sci. USA. 86:2766-2770.

25. Orita, M., H. Iwahana, H. Kanazawa, and T. Sekiya. 1989. Detection of polymorphism of human DNA by gel electrophoresis as single strand conformation polymorphisms. Proc. Natl. Acad. Sci. USA. 86:2766-2770.

26. Suzuki, Y., M. Orita, M. Shiraishi, K. Hayashi, and T. Sekiya. 1990. Detection or ras gene mutations in human lung cancers by single strand conformation polymorphism analysis of polymerase chain reaction products. Oncogene. 5:1037-1043.

27. Hansen, J. A., S. M. Hu, P. Antonelli, M. Kamoun, J. N. Hurley, R. J. Winchester, B. Dupont, and H. G. Kunkel. 1979. B-lymphoid cell lines derived from HLA-D homologous donors. Immunogenetics. 8:51-64.

28. Southern, E. M. 1975. Detection of specific sequences among DNA fragments separated by gel electrophoresis. J. Mol. Biol. 98:503-517.

29. Saiki, R. K., T. I. Bugawan, G. T. Horn, K. B. Mullis, and H. A. Erlich.
1986. Analysis of enzymatically amplified b-globin and HLA-DQA DNA using allele specific oligonucleotide probes. Nature (Lond.). 324:163-166.

30. Dean, M., M. B. White, J. Amos, B. Gerrand, C. Stewart, K. T. Khaw, and M. Leppert. 1990. Multiple mutations in highly conserved residues are found in mildly affected cystic fibrosis patients. Cell. 61:863-870.

31. Cawthon, R. M., R. Weiss, G. Xu, D. Viskochil, M. Culver, J. Stevens, M. Robertson, D. Dunn, R. Gesteland, P. O'Connel, and R. White. 1990. A major segment of the neurofibromatosis type I gene: cDNA sequence, genomic structure, and point mutations. Cell. 62:193-201.

32. Orita, M., T. Sekiya, and K. Hayashi. 1990. DNA sequence polymorphisms in Alu repeats. Genomics. 8:271-278.

33. Berta, P., J. R. Howkins, A. H. Sinclair, A. Taylor, B. L. Griffiths, P. N. Goodfellow, and M. Fellous. 1990. Genetic evidence equating SRY and the testisdetermining factor. Nature (Lond.). 348:448-450.

34. Collier, S., P. J. Sinnott, P. A. Dyer, D. A. Price, R. Harris, and T. Strachan. 1989. Pulse field gel electrophoresis identifies a high degree of variability in the number of tandem 21 -hydroxylase and complement $C 4$ gene repeats in 21 -hydroxylase deficiency haplotypes. EMBO (Eur. Mol. Biol. Organ.) J. 8:13931402.

35. Jeffreys, A. J., V. Wilson, and S. L. Thelin. 1985. Individual fingerprints of human DNA. Nature (Lond.). 316:76-79.

36. Tajima, T., K. Fujieda, and Y. Fujii-Kuriyama. 1993. De novo mutation causes steroid 21 hydroxylase deficiency in one family of HLA-identical affected and unaffected siblings. J. Clin. Endocrinol. Metab. 77:86-89.

37. Rodrigues, N. R., I. Dunham, C. Y. Yu, M. C. Carroll, R. R. Porter, and R. Campbell. 1987. Molecular characterization of HLA-linked steroid 21-hydroxylase B gene from an individual with congenital adrenal hyperplasia. EMBO (Eur. Mol. Biol. Organ.) J. 6:1653-1661.

38. Collier, S., T. Mayada, and T. Strachan. 1993. A de novo pathological point mutation at the 21-hydroxylase locus: implications for gene conversion in the human genome. Nature Genetics. 3:260-264.

39. Sinnott, P., P. A. Dyer, D. A. Price, R. Harris, and T. Strachan. 1989. 21-hydroxylase deficiency families with HLA identical affected and unaffected sibs. J. Med. Genet. 26:10-17.

40. Owerbach, D., L. Sherman, A. L. Ballard, and R. Azziz. 1992. Pro-453 to Ser mutation in CYP21 is associated with nonclassical steroid 21-hydroxylase deficiency. Mol. Endocrinol. 6:1211-1215.

41. Helmberg, A., M. T. Tusie-Luna, M. Tabarelli, R. Kolfer, and P. C. White. 1992. R339H and P453S: CYP21 mutations associated with nonclassic steroid 21-hydroxylase deficiency that are not apparent gene conversions. $\mathrm{Mol}$. Endocrinol. 6:1318-1322. 